\title{
Kafkas Vaşağında (Lynx lynx dinniki) Nervus Phrenicus’un Orijini, Seyri ve Dağılımı
}

\author{
Hasan Hüseyin ARI ${ }^{1,2 a}$ Lutfi TAKCI ${ }^{1 b}$ Nilgün KURU ${ }^{1 \mathrm{c}}$ \\ ${ }^{1}$ Sivas Cumhuriyet Üniversitesi Veteriner Fakültesi Anatomi Anabilim Dal, Sivas, TÜRKIYE \\ ${ }^{2}$ Kırgızistan-Türkiye Manas Üniversitesi Veteriner Fakültesi Anatomi Anabilim Dalı, Bişkek, KIRGIZISTAN \\ ${ }^{a}$ https://orcid.org/0000-0001-7168-4014, ${ }^{b}$ https://orcid.org/0000-0002-8865-8186 \\ ${ }^{c}$ https://orcid.org/0000-0003-2778-6181
}

*Sorumlu yazar: $\underline{\text { takci@cumhuriyet.edu.tr }}$

\section{ÖZET}

$\mathrm{Bu}$ araştırma, Kafkas vaşaklarının (Lynx lynx dinniki) nervus phrenicus'unun orijin, seyir ve dağılımını makroanatomik olarak açığa çıkarmak amacı ile yapılmıștır. Bu amaçla üç dişi ölü hayvan materyalinin damar sistemi temizlendikten sonra \%10 formaldehit ile kadavrası hazırlandı. Daha sonra bu materyallerin çift taraflı nervus phrenicus'u canalis vertebralis'ten çıkıș yerinde, boyunda ve cavum thoracica'da diseke edildikten sonra sinirin orijini, seyri ve dağılımı fotoğraflanmıştır. Elde edilen resimler fotoğraf işleme programında bilgisayarda işlenerek bu makalede sunulmuştur. Araştırma sonucunda, 6. ve 7. servikal spinal sinirlerin ventral dallarının canalis vertebralis'i terk ettiği, nervus phrenicus'un omurganın ventralinde 8 . servikal spinal sinir seviyesinde bu sinirlerin ventral dallarının birleşmesinden oluștuğu görülmüștür. Boyun bölgesinde trachea'nın sağ ve solunda seyreden sinirin apertura thoracica cranialis'ten cavum thoracica'ya girdiği, mediastinum craniale'de arteria subclavia dextra ve sinistra ile vena cava cranialis arasından geçtiği ve bu bölgede pericardium'a bir dal verdiği belirlenmiştir. Mediastinum medium'da basis cordis'in üzerinden, v. cava cranialis ve aorta'nın dallarına komşu olarak mediastium caudale'ye ulaştığı, burada akciğerin mediastinum'a bakan yüzünde caudale doğru seyrederek centrum tendineum'a vardığ 1 ve centrum tendineum'un kubbe bölümünün solundan diaphragma'ya girdiği tespit edilmiştir. Nervus phrenicus'un diaphragma'da centrum tendineum üzerinde dorsal ve ventral dallara ayrılarak diaphrama'nın pars muscularis'ine dağıldığı görülmüştür. $\mathrm{Bu}$ araştırmada, Kafkas vaşağının nervus phrenicus'unun boyunda, mediastinum craniale, medium ve caudale'deki seyri ile diaphragma'daki dağılımının kedilerdeki dağılımı benzemesine rağmen sinirin oluşumuna kedilerden farklı olarak 4. ve 5. servikal spinal sinirlerin katılmadığı saptanmıştır. Yabani hayvanlarda plexus brachialis'i oluşturan spinal sinirlerin ventral dalları ve bu plexus'tan çıkan dalların seyri, dağılımı üzerine daha fazla araştırma yapmak gerektiği kanaatine varılmıştır.

\section{MAKALE BİLG İS İ}

\section{Araştırma Makalesi}

Geliş : 25.10.2021

Kabul: 03.11.2021

Anahtar kelimeler: Vaşak, anatomi, makroanatomi, nervus phrenicus, diaphragma

\section{Origin, Courses and Distribution of The Phrenic Nerve in The Caucasian Lynx}

\section{(Lynx lynx dinniki)}

\section{A B S T R A C T}

This research was carried out to reveal macroanatomically the origin, course and distribution of nervus phrenicus of Caucasian lynx (Lynx lynx dinniki). For this purpose, after cleaning the vascular system of three female dead animal materials, cadavers were prepared with $10 \%$ formaldehyde. Then, the origin, course and distribution of the bilateral nervus phrenicus of these materials were photographed after leaving the canalis vertebralis. It was observed that the ventral branches of the 6th and 7th cervical spinal nerves left the canalis vertebralis, and the nervus phrenicus was formed by the merger of the ventral branches of these nerves at the level of the 8th cervical spinal nerve in the ventral of the spine. It has been determined that the nerve running to the right and left of the trachea in the neck region enters the cavum thoracica, passes between the arteria subclavia dextra and sinistra and vena cava cranialis in the mediastinum craniale and gives a branch to the pericardium in this region. . It was determined that it reaches the mediastium caudale adjacent to the branches of the cava cranialis and aorta via basis cordis in mediastinum medium, where it travels caudally on the face of the lung facing the mediastium, reaches the centrum tendineum. It has been observed that the nervus phrenicus divides into dorsal and ventral branches on the centrum tendineum and distributes to the pars muscularis of the diaphragm. In this study, although the distribution of the nervus phrenicus of the Caucasian lynx is similar in cats, it was determined that the 4th and 5th cervical spinal nerves did not participate in the formation of the nerve, unlike in cats. More research is needed on the course and distribution of the ventral branches of the spinal nerves forming the plexus brachialis in wild animals.
ARTICLE INFO

Research Article

Received: 25.10.2021

Accepted: 03.11.2021

Keywords:

Bobcat, anatomy, macroanatomy, phrenic nerve, diaphragm

To Cite: $\quad$ Arı HH, Takcı L, Kuru N 2021. Kafkas Vaşağında (Lynx lynx dinniki) Nervus Phrenicus'un Orijini, Seyri ve Dağılımı, MJAVL Sciences. 11 (2) 172-178 


\section{GíRIŞ}

Avrasya vaşağının (Lynx lynx) bir alt türü olan Kafkas vaşağı (Lynx lynx dinniki) Türkiye, Kafkasya ve İran'da dağılım gösteren ve soyu tükenme tehlikesi altında olan bir yabani kedi türüdür (Hunter 2015; Sunquist and Sunquist 2017; Ozgel and Aykut 2015). Vücuduna oranla hafif gövdesi, uzun bacakları ve siyah tüylerle sonlanan kısa kuyruğu diğer vaşaklarda bulunan tür özellikleri olarak sayılmaktadır (Hunter 2015; Sunquist and Sunquist 2017). Arka bacaklarının ön bacaklardan uzun olması, kendine has eğimli sırt görünümü ve kışın karda hareketi kolaylaştırmak için yoğun kıllarla örtülü pençeler de vahşi kedilerin özellikleri olarak sayılmaktadır (Sunquist and Sunquist 2017; Hunter 2015). Tüm vaşak türleri içerisinde en ağır başa sahip olan bu türde ayrıca kulakların ucundan uzanan siyah tutamları bulunmaktadır (Sunquist and Sunquist 2017; Hunter 2015). Değişik renk tonlarında kürklere sahip olan kedilerin kürklerindeki beneklenme de yaşadığı çevre ve iklim şartlarına göre değişim göstermektedir. Kafkas vaşağında üst çenedeki ön öğütücü dişlerin her çene yarımında diğer kedilerden farklı olarak bir eksik olmasının en önemli ayırıcı anatomik fark olduğu belirtilmektedir (Hansen 2007; Feldhamer et al. 2003; Kitchener 1991). Premolar dişlerin 3 yerine 2 adet bulunması ağızda bulunan diş sayısının da 30 yerine 28 adet olması sonucunu doğurmaktadır (Hansen 2007; Feldhamer et al. 2003; Kitchener 1991).

Nervus (n) phrenicus hayvan türleri arasında farkl1lıklar göstermekle birlikte 5-7. servikal spinal sinirlerin (C) ventral dallarından köken alan ve diaphragma'nın innervasyonundan sorumlu olan sinir olarak tarif edilmektedir (König et al. 2007; Dursun 2008). Siniri temelde C6'nın ventral dalının oluşturduğu ve sinirin oluşumuna C5 ve C7'nin ventral dallarının da katkıda bulunduğu belirtilmektedir (Dursun 2008). Ayrıca, kedilerde bu sinirin oluşumuna C4'ün de katıldığı bildirilmiştir (König et al. 2007). İnsanda, bu siniri 3-5. servikal spinal sinirlerin ventral dalları meydana getirmektedir (Nason et al. 2012). Siniri oluşturan motor lifler, diaphragma'nın motor innervasyonunu sağlarken, rami pericardiaci adı verilen sensitif lifleri ise basis cordis bölgesinde pericardium serosum ile pericardium fibrosum'un duyusunu almaktadır (Dursun 2008).

Diaphragma ventilasyonun gerçekleşmesinde görev alan en önemli kastır. Herhangi bir sebeple diaphragma'da meydana gelecek bir fonksiyon kaybı canlılarda solunum güçlüğüne neden olmaktadır. Kasın innervasyonunu sağlayan n. phrenicus'un felce uğraması solunum güçlüğü meydana getirmektedir (Nason et al. 2012). Hem medulla spinalis'ten ayrıldığı bölge hem de göğüs boşluğundaki seyri, n. phrenicus'un bu bölgelerde yapılacak operatif girişimlerden etkilenmesini kaçınılmaz hale getirmektedir (Aguirre et al. 2013; Canbaz et al. 2004). N. phrenicus'un kökenini, seyrini ve diaphragma'da dağılımını bilmenin bölgede yapılacak operatif girişimler için kılavuzluk yapması açısından önemli olduğu vurgulanmaktadır (Aguirre et al. 2013; Canbaz et al. 2004; Tripp and Bolton 1998; Efthimiou et al. 1991; Markand et al. 1985). Literatürde vaşakta n. phrenicus'un orijini ve seyri ile ilgili bir çalışmaya rastlanmamıştır. Çalışmanın amacı Avrasya vaşağının (lynx lynx) Türkiye'de görülen alt türü olan Kafkas vaşağında (Lynx lynx dinniki) n. phrenicus'un kökeni ve seyrini ortaya koymak ve muhtemel farklılıkları tartışmaktır.

\section{MATERYAL VE METOT}

Çalışmada; doğal sebeplerden ölen ve Doğa koruma ve Milli Parklar Sivas Şubesi tarafindan Sivas Cumhuriyet Üniversitesi Veteriner Fakültesi Anatomi Anabilim Dalı’na getirilen ağırlıkları 6.9 kg, $7.6 \mathrm{~kg}, 7.8 \mathrm{~kg}$ olan üç adet erişkin dişi vaşak materyal olarak kullanıldı. Ölümlerinden sonra hızlı bir şekilde Anatomi laboratuvarına getirilen vaşakların arteria (a) carotis communis'leri açıldıktan sonra bu damara yerleştirilen kateter ile hidrojen peroksit ve serum fizyolojikten oluşan karışım verilerek arteriyel sistemdeki kan temizlendi. Sonra aynı damarlar kullanılarak hayvanların organ ve dokularını fikse etmek için \%10'luk formaldehit solüsyonu verildi. Uygun diseksiyon yöntemleri kullanılarak göğüs boşlukları açılan vaşaklarda n. phrenicus'un diaphragma'da dağılan dalları merkeze doğru takip edildi. Sinirin medulla spinalis'deki kökleri bulundu. Servikal spinal sinirlerin ventral dalları başa kadar açılarak sayıldı. N. phrenicus'un kökeni ve seyri huawei marka fotoğraf makinası ile fotoğraflandı. Sinir ve dalların adlandırmasında Nomina Anatomica Veterinaria (NAV) (2012) kullanıldı. Elde edilen bulgular literatür ışığında tartışıldi. 


\section{BULGULAR VE TARTIŞMA}

Anadolu vaşağında n. phrenicus’un hem sağ tarafta hem de solda C6 ve C7'den köken aldığı tespit edildi (Şekil 1, 2).

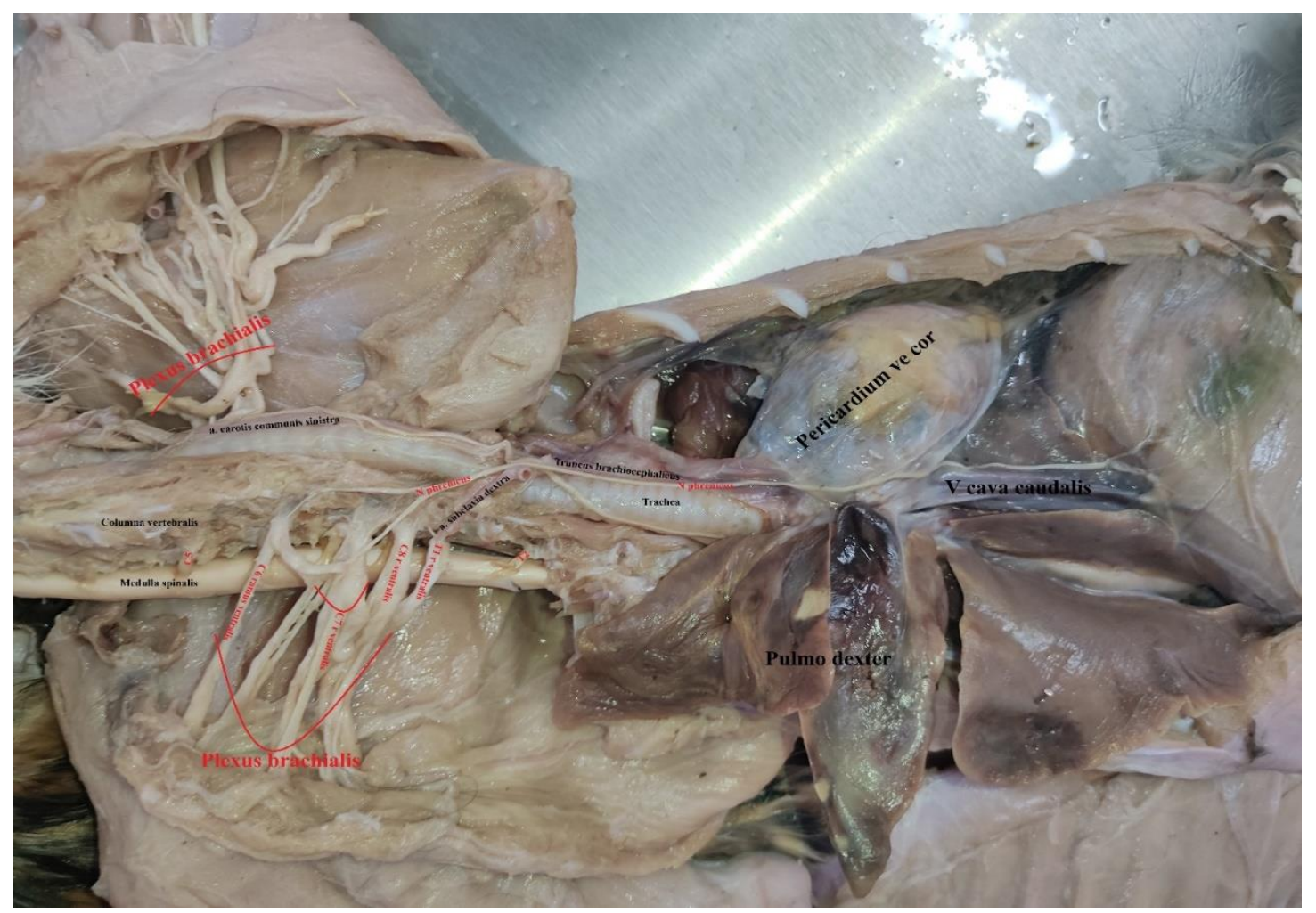

Şekil 1. Nervus phrenicus dexter'in kökeni ve seyri.

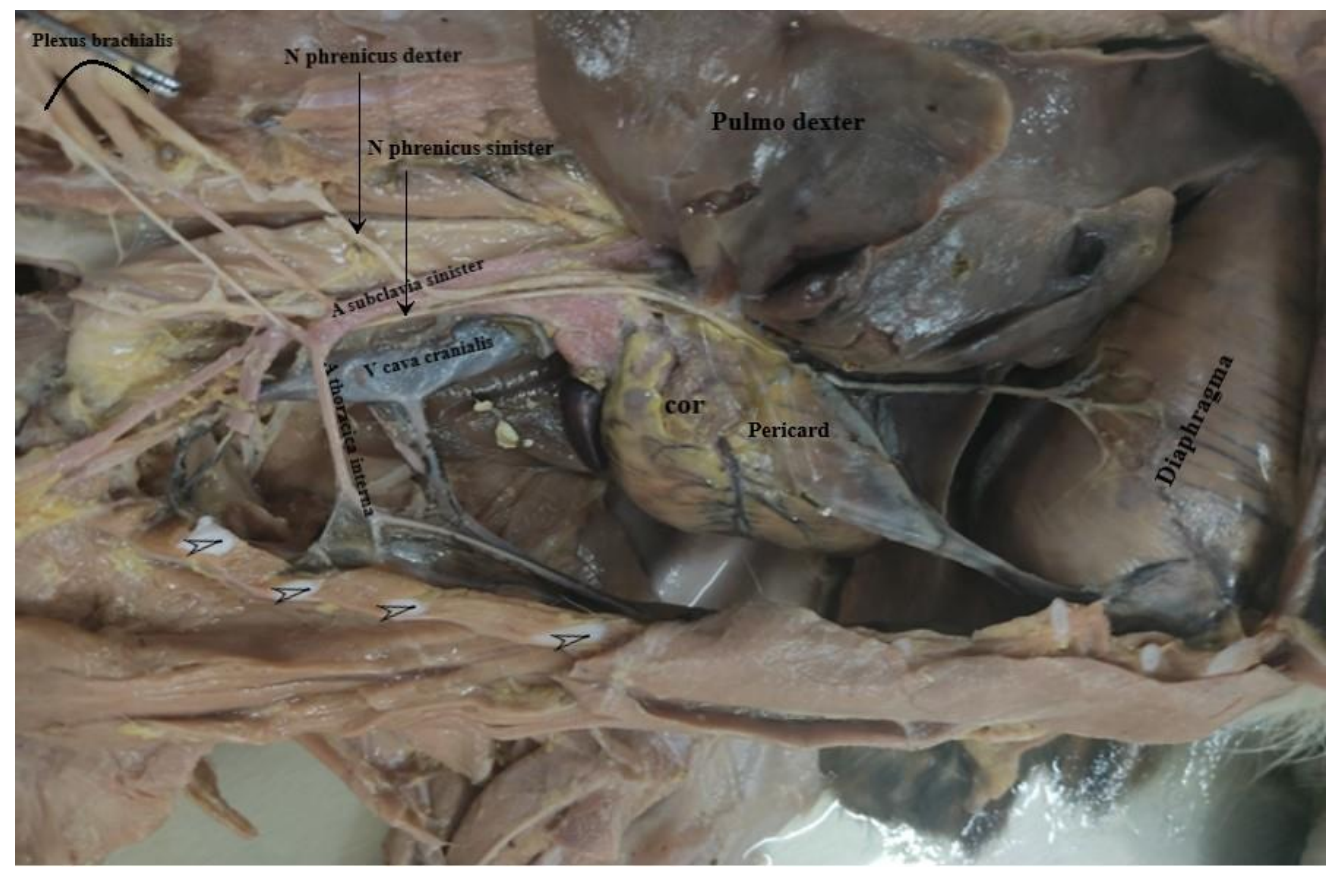

Şekil 2. Nervus phrenicus sinister'in kökeni ve seyri. Oklar: cartilago costae

Bu dalların sağda C8 seviyesinde 7. servikal omur hizasında birleştiği görüldü (Şekil 1). Nervus phrenicus sinister’i oluşturacak olan C6 ve C7'nin ventral dallarının ise 6. servikal omur hizasında birleştiği belirlendi (Şekil 2). Servikal bölgede sulcus jugularis içerisinde trachea'nın sağından ve solundan seyreden n. phrenicus’un göğüs boşluğuna girdiği 
görüldü (Şekill,2). Nervus phrenicus dexter'in mediastinum craniale'de a. subclavia dextra ile vena (v) cava cranialis'in arasından geçtiği ve mediastinum mediale'ye ulaştı̆̆ saptandı. Mediastinum mediale'de sinirin basis cordis üzerinden geçtikten sonra mediastinum caudale'ye ulaştığ 1 tespit edildi (Şekil 1). Mediastinum caudale'de v. cava caudalis'in ventralinde kısa bir seyir izledikten sonra centrum tendineum'un kubbesinin biraz sağından diaphragma'ya giren sinirin, crus dexter ve onun devamı olan bölümünde dağıldığı tespit edildi. (Şekil 3).

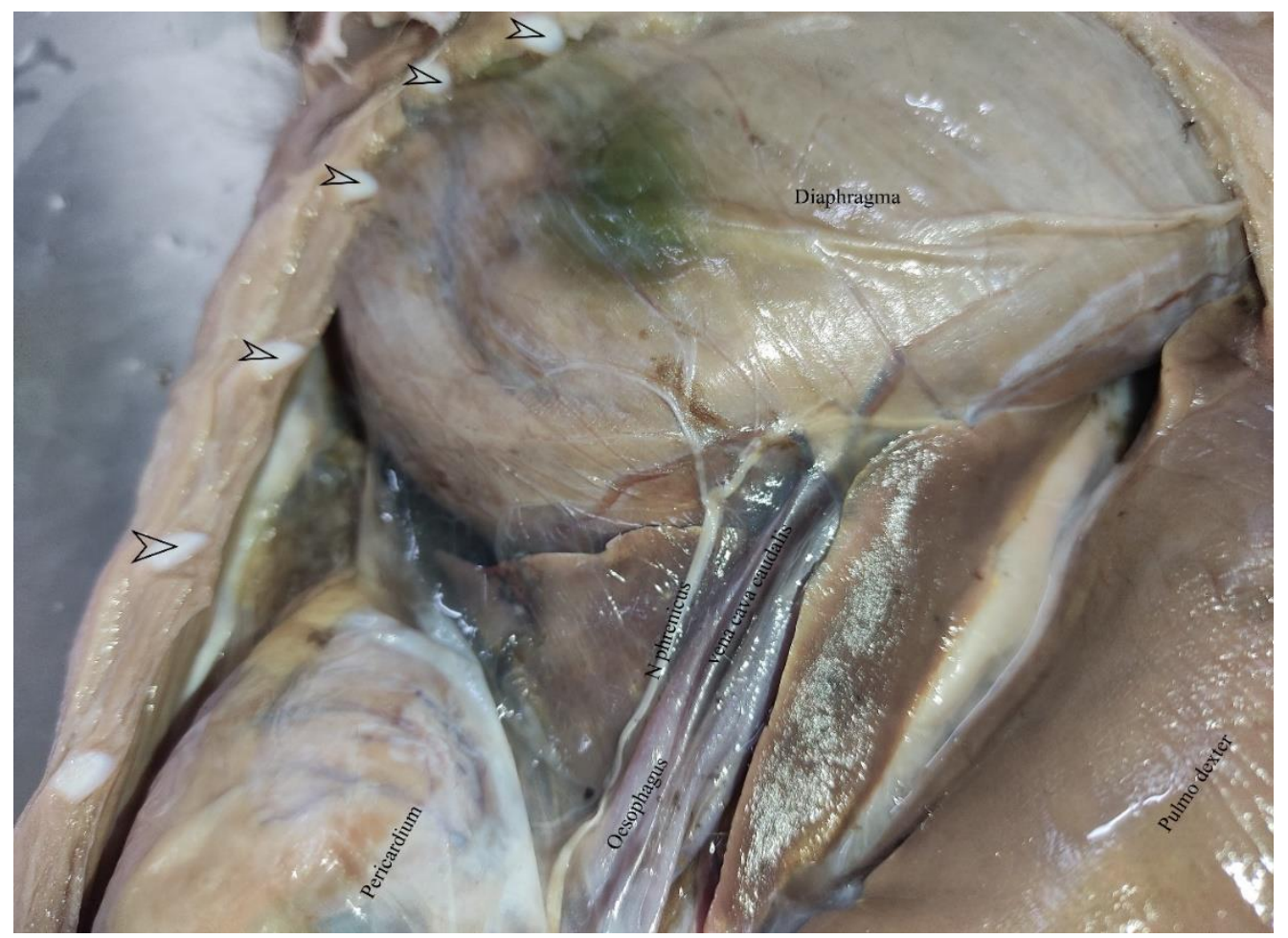

Şekil 3. Nervus phrenicus dexter'in diaphragma'da dağılımı Oklar: cartilago costae

Seyri sırasında n. phrenicus'un basis cordis bölgesinde pericardium'dan aldığg sensitif lifler görüntülendi. (Şekil 4).

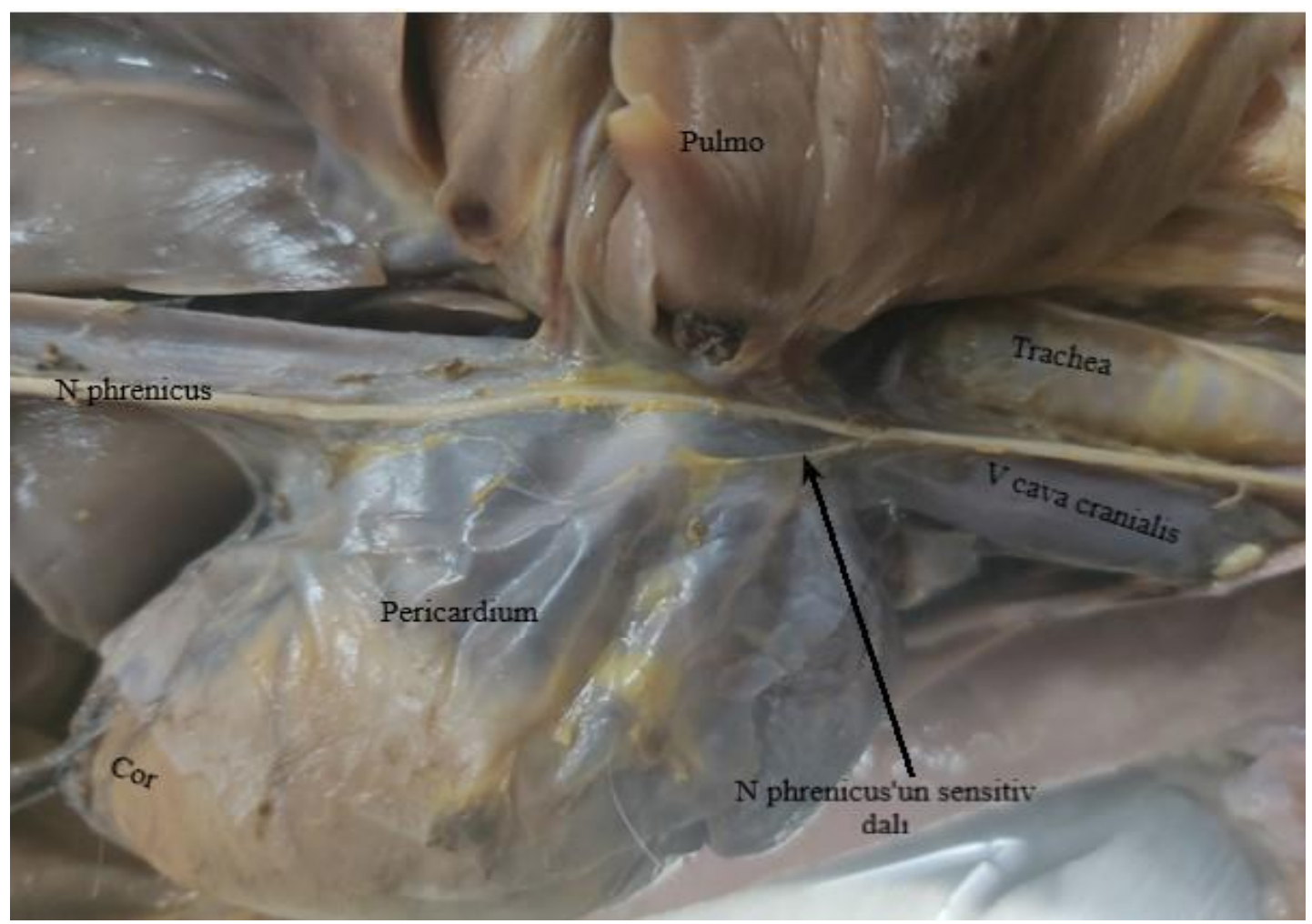


Şekil 4. Nervus phrenicus sinister'in mediastinum medium'daki seyri.

N. phrenicus sinister'in C6 ve C7'den aldığı dallar C7 hizasında ve 6. torakal omurun hizasına denk gelecek şekilde birleştikten sonra ventrale doğru bir seyir izleyerek a. thoracica interna ile a. axillaris'in ayrım noktasından geçtiği görüldü (Şekil 2). A. subclavia'nın ventralinde ve ona paralel bir seyir izleyerek göğüs boşluğuna giren sinirin mediastinum medium'da akciğerin ön lobu ile kalbin basis cordis'i arasından geçtiği tespit edildi. Mediastinum caudale'de bağımsız seyreden sinirin sağ tarafta olduğu gibi centrum tendineum'un kubbeli bölümünün biraz solundan diaphragma'ya girerek dallandığı belirlendi (Şekil 5)

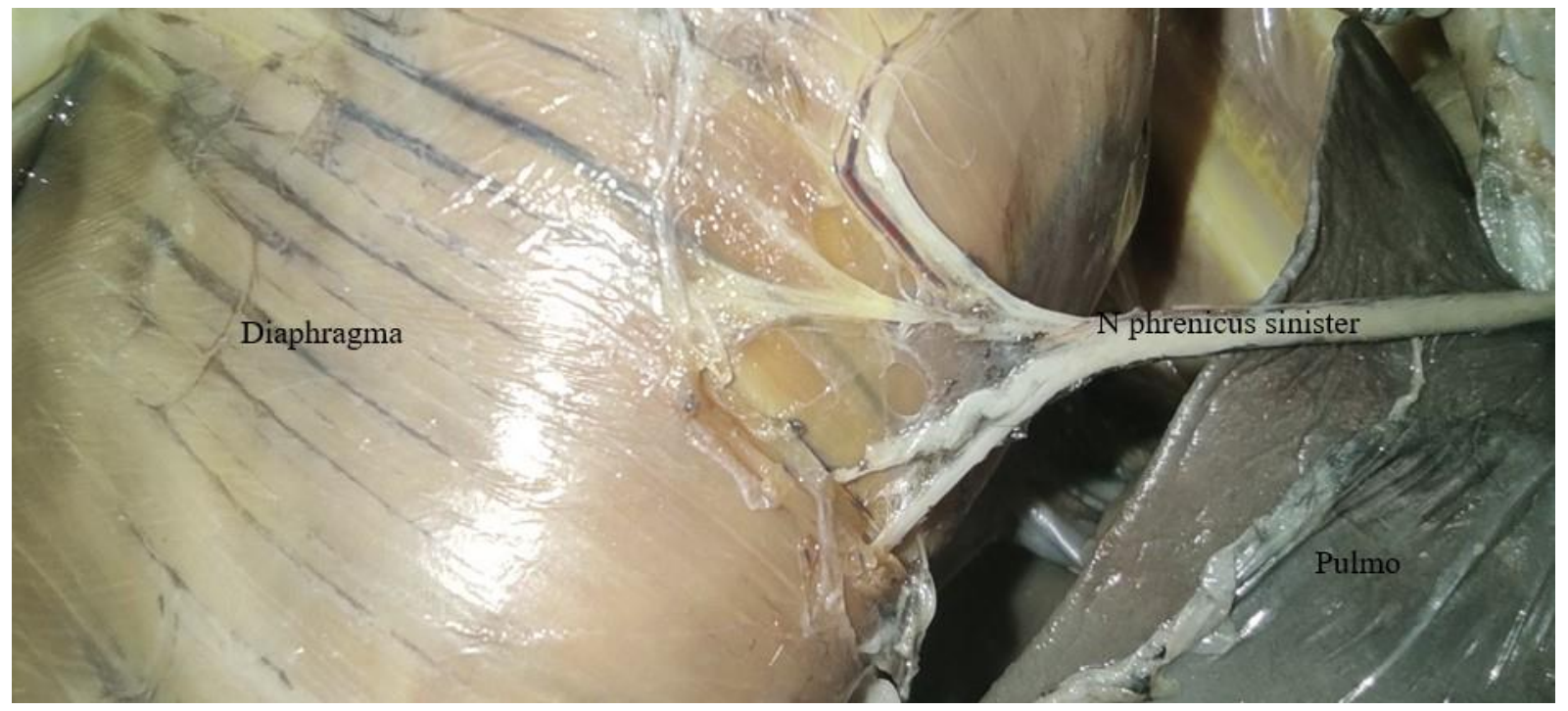

Şekil 5. Nervus phrenicus sinister'in diaphragma'da dağılımı.

Sinirin oluşumundan diaphragma'da dağılmasına kadar izlediği yol boyunca trachea, truncus brachiocephalicus'un dalları (a. subclavia dextra, sinistra), v.cava cranialis, basis cordis (pericardium), v. cava caudalis ve akciğer ile temasta olduğu görüldü. (Şekil 1,2).

\section{TARTIŞMA}

Evcil memelilerde n. phrenicus'un C5-C7'den oluştuğu (Dursun 2008; König et al. 2007) ve kedilerde C4'ten de dal aldığı bildirilmiştir (König et al. 2007). Çalışmamızda sinirin C6 ve C7'nin ventral dalları tarafından oluşturulduğu, ancak evcil kedilerden farklı olarak C4 ve C5'in ventral dallarının n. phrenicus'un oluşumuna katılmadığ belirlenmiştir. Bu durum evcil kedi ile vaşak arasında n. phrenicus'un orijini açısından bir fark ortaya çıkarmıştır.

Evcil memeli hayvanlarda C5-7'den gelen sinir lifleri m. scalenus'un bulunduğu bölgede birleşerek n. phrenicus'u oluşturmaktadır (Dursun 2008; Dyce et al. 2010). Çalışmamızda C6 ve C7'den gelen dalların C8'in medulla spinalis'ten ayrıldığı seviyede birleşerek n. phrenicus'u oluşturdukları tespit edilmiştir (Şekil 1). Elde edilen bulgunun literatürde tarif edilen bölge ile uyumlu olduğu görülmektedir.

Anatomi atlaslarında $\mathrm{n}$. phrenicus dextra'nın seyri sırasında v. cava cranialis'in lateral'inden basis cordis üzerine geçtiği görülmektedir (Dyce et al. 2010; Dursun 2008; Hudson and Hamilton 2017). N. phrenicus sinistra truncus brachiocephalicus ile truncus pulmonalis'in solunda n. vagus'un altında seyretmektedir (Hudson and Hamilton 2017; Dursun 2008; Dyce et al. 2010). Çalışmamızda da literatürde belirtilen seyre benzer olduğu görülmektedir (Şekil 1,2).

N. phrenicus sensorik ve motor lifler taşımaktadır (Dursun 2008). Motor lifleri diaphragma'yı innerve etmektedir. Sensorik lifler ise pericardium'un duyusunu almaktadır. Çalışmamızda sinirin basis cordis üzerinden geçerken pericardium'dan katılan lifleri ile diaphragma'da dağılan dalları görülmektedir (Şekil 4).

İnsanda n. phrenicus ile ilgili yapılan çalışmalar incelendiğinde göğüs boşluğunda yapılan cerrahi operasyonlarda bu sinirin yaralanmalarına sık rastlandığı belirtilmektedir (Aguirre et al. 2013; Canbaz et al. 2004; Efthimiou et al. 1991; Markand et al. 1985; Tripp and Bolton 1998). Bu durumun önüne geçebilmek için sinirin seyrinin bilinmesinin ne denli önemli olduğu da özellikle vurgulanmaktadır (Efthimiou et al. 1991; El-Boghdadly et al. 2017; Markand et al. 1985; Tönz et al. 1996; Tripp and Bolton 1998). Diaphragma gibi solunumda önemli fonksiyonu olan bir kasin innervasyonunda meydana gelebilecek bir kesinti, aksama, veya felcin ortaya çıkaracağı hasar ile ilgili de birçok çalışma yapılmıştır (Efthimiou et al. 1991; Nason et al. 2012). Ancak hayvanlarda göğüs boşluğu cerrahisindeki 
ilerlemenin insan ile aynı seviyede olmaması sebebi ile literatürde konu ile ilgili yapılan çalışmaların hem çok az hem de daha yüzeysel kaldığı görülmüştür. Bu bağlamda çalışmamızın gelecekte yapılacak çalışmalar için kılavuzluk yapması beklenmektedir. Ayrıca, sinirin seyrinin evcil kedilerdeki seyrine benzerlik gösterdiği ancak evcil kedilerde $\mathrm{n}$. phrenicus'a katkısı olan C4 ve C5' in ventral dallarının vaşakta sinirin oluşumuna katılmadığı tespit edilmiş̧ir (Şekil 1, 2).

Literatürde evcil kedilerde n. phrenicus'un kökenini kadavradan gösteren bir fotoğrafa rastlanmamıştır (Done et al. 2009; Hudson and Hamilton 2017). N. phrenicus sinister'in seyrinin (Done et al. 2009) çalışmadaki bulgularla uyumlu olduğu görülmektedir. Sinirin diaphragmada dağıldığı bölge evcil kedilerde centrum tendineum'un merkezi olarak gösterilmiş̧ir (Hudson and Hamilton 2017). Çalışmamızda sinirin diaphragma'ya en kubbeli olan yerden değil de biraz daha sağından ve solundan girdiği tespit edilmiştir. Bu küçük fark dışında sinirin seyrinin evcil kedi (Done et al. 2009;

Hudson and Hamilton 2017) ile uyumlu olduğu görülmektedir.

\section{SONUÇ}

Çalışmada Türkiye'de görülen Kafkas vaşağının (Lynx lynx dinniki) n. phrenicus'unun kökeni, seyri ve dağılımı ortaya konulmuştur. Elde edilen bulgular mevcut literatür ışığında tartışılmış ve sinirin orijini bakımından evcil kedilerle farklılık arz ettiği belirlenmiştir. N. phrenicus'un kedigillerde seyri ve dağılımı açısından literatürün yetersiz olduğu görüldüğ̈nden çalışmanın konu ile ilgili bilgi eksikliğini tamamlayacağı düşünülmektedir.

\section{ÇIKAR ÇATIŞMASI}

Yazarlar, bu yazı ile ilgili herhangi bir çıkar çatışması olmadığını beyan ederler.

\section{YAZAR KATKISI}

Tüm yazarlar eşit katkıya sahiptir.

\section{KAYNAKLAR}

Aguirre, Victor J, Priyanka Sinha, Adam Zimmet, Geraldine A Lee, Lachlan Kwa, and Franklin Rosenfeldt. 2013. 'Phrenic nerve injury during cardiac surgery: mechanisms, management and prevention', Heart, Lung and Circulation, 22: 895-902.

Canbaz, Suat, Nilda Turgut, Umit Halici, Kemal Balci, Turan Ege, and Enver Duran. 2004. 'Electrophysiological evaluation of phrenic nerve injury during cardiac surgery-a prospective, controlled, clinical study', BMC surgery, 4: $1-5$.

Done, Stanley H, Peter C Goody, Susan A Evans, and Neil C Stickland. 2009. Color Atlas of Veterinary Anatomy, Volume 3, The Dog and Cat E-Book (Elsevier Health Sciences).

Dursun, Necdet. 2008. Veteriner Anatomi III (Medisan Yayınevi: Ankara).

Dyce, KM, WO Sack, and CJG Wensing. 2010. 'Textbook of Veterinary Anatomy 4th (Edn.)', Saunders Elsevier: 71-78.

Efthimiou, John, John Butler, Colin Woodham, Malcolm K Benson, and Stephen Westaby. 1991. 'Diaphragm paralysis following cardiac surgery: role of phrenic nerve cold injury', The Annals of thoracic surgery, 52: 1005-08.

El-Boghdadly, Kariem, Ki Jinn Chin, and Vincent WS Chan. 2017. 'Phrenic nerve palsy and regional anesthesia for shoulder surgery: anatomical, physiologic, and clinical considerations', Anesthesiology, 127: 173-91.

Feldhamer, George A, Bruce Carlyle Thompson, and Joseph A Chapman. 2003. Wild mammals of North America: biology, management, and conservation (JHU Press).

Hansen, Kevin. 2007. Bobcat: master of survival (Oxford University Press).

Hudson, Lola, and William Hamilton. 2017. Atlas of feline anatomy for veterinarians (CRC Press).

Hunter, Luke. 2015. Wild cats of the world (Bloomsbury Publishing).

Kitchener, Andrew. 1991. The natural history of the wild cats (Comstock Pub. Associates).

König, Horst Erich, Hans-Georg Hans-Georg, and H Bragulla. 2007. Veterinary anatomy of domestic mammals: textbook and colour atlas (Schattauer Verlag).

Markand, Omkar N, SS Moorthy, Yousuf Mahomed, Robert D King, and John W Brown. 1985. 'Postoperative phrenic nerve palsy in patients with open-heart surgery', The Annals of thoracic surgery, 39: 68-73.

Nason, Laura K, Christopher M Walker, Michael F McNeeley, Wanaporn Burivong, Corinne L Fligner, and J David Godwin. 2012. 'Imaging of the diaphragm: anatomy and function', Radiographics, 32: E51-E70.

Ozgel, Ozcan, and Mevlut Aykut. 2015. 'Macroanatomical investigation on the ossa membri pelvini of Anatolian bobcat, Lynx lynx', Pakistan J Zool, 47: 1492-94.

Sunquist, Mel, and Fiona Sunquist. 2017. Wild cats of the world (University of chicago press). 
Art et al. / Manas Journal of Agriculture Veterinary and Life Sciences 11 (2) (2021) 172-178

Tönz, Martin, Ludwig K von Segesser, Tomislav Mihaljevic, Urs Arbenz, Urs G Stauffer, and Marko I Turina. 1996. 'Clinical implications of phrenic nerve injury after pediatric cardiac surgery', Journal of pediatric surgery, 31: 126567.

Tripp, Lt Col Henry F, and Lt Col JW Randolph Bolton. 1998. 'Phrenic nerve injury following cardiac surgery: a review', Journal of cardiac surgery, 13: 218-23. 